\title{
The residual cardiorenal risk in type 2 diabetes
}

\author{
Dario Giugliano ${ }^{1,2^{*}} \mathbb{D}$, Maria Ida Maiorino ${ }^{3}$, Giuseppe Bellastella and Katherine Esposito ${ }^{3}$
}

\begin{abstract}
In this commentary, we introduce the concepts of removed and residual risks in conditioning thecardiorenal outlook of patients with type 2 diabetes (T2D). The removed cardiorenal risk represents the risk of progression of CV events (major adverse cardiovascular events, MACE; heart failure, HF) and diabetes kidney disease (DKD) taken away by optimal glycemic control or the use of newer antihyperglycemic drugs (glucagon-like peptide-1 receptor agonists, GLP-1RA, andsodium-glucose transporter-2 inhibitors, SGLT-2i) in patients with T2D, as demonstrated by the results of intensive glucose lowering trials (IGT) and cardiovascular outcome trials (CVOT). IGT have shown that successful glycemic control has modest benefits, as the removed cardiorenal risk ranges from 9\% for MACE, to $20 \%$ for progression of DKD and to 0\% for HF. The removed risk of MACE is 13\% for GLP-1RA and 12\% for SGLT-2i. However, SGLT-2i, as compared with GLP-1RA, removed twofold more risk (39\% vs 17\%) for kidney outcomes and fourfold more risk (33\% vs 9\%) for HF. Dipeptidyl peptidase-4 inhibitors have no clinically important cardiorenal benefits, as residual risk is 99\% for MACE, 100\% for kidney outcomes (excluding new albuminuria), and $100 \%$ for HF. Although the results of some real world, population-based cohort studies suggest the possibility that the cardiorenal protection afforded by newer antihyperglycemic drugs is additive to that of optimal glycemic control, only specific randomized controlled trials could answer this question.
\end{abstract}

Cardiovascular $(\mathrm{CV})$ disease is the leading cause of morbidity and mortality for people with type 2 diabetes (T2D), resulting from the likely association and contribution of many risk factors, including although not limited to hypertension, dyslipidemia, obesity and diabetes itself. Large benefits are seen when multiple CV risk factors are addressed simultaneously. For instance, patients with T2D who had five risk-factor variables within the target ranges had little [1] or no excess [2] CV risk as compared with the general population, with the notable exception of heart failure (HF) which seems unrelated to major metabolic and $\mathrm{CV}$ risk factors. Unfortunately, only $5-6 \%$ of people with T2D had optimal risk factor control $[1,2]$. Diabetic kidney disease (DKD) occurs in

\footnotetext{
*Correspondence: dario.giugliano@unicampania.it

${ }^{1}$ Division of Endocrinology and Metabolic Diseases, Department

of Advanced Medical and Surgical Sciences, University of Campania Luigi Vanvitelli, Naples, Italy

Full list of author information is available at the end of the article
}

$20-40 \%$ of patients with diabetes [3] and is the leading cause of end stage kidney disease (ESKD) in the U.S. Its diagnosis is mainly based on the persistent presence of elevated urinary albumin excretion (albuminuria), low estimated glomerular filtration rate (eGFR), or both. The presence of DKD in T2D has a role in perpetuating the development of adverse CV outcomes [4], although it often does not gain appropriate consideration by clinicians. DKD is an important contributing factor to $\mathrm{CV}$ and all-cause mortality, to such an extent that it may be recognized as a coronary heart disease risk equivalent [5]. Accordingly, diabetic vascular complication-related deaths had increased substantially during 2000-2016, mainly driven by the increased mortality of kidney complications [6].

Diabetes is defined by a hyperglycemic status: intuitively, glycemic control has long been though fundamental to diabetes management for reducing diabetes complications. Intensive glycemic control (IGC), with the

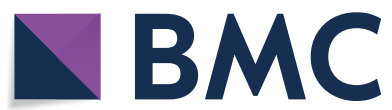

(c) The Author(s) 2021. This article is licensed under a Creative Commons Attribution 4.0 International License, which permits use, sharing, adaptation, distribution and reproduction in any medium or format, as long as you give appropriate credit to the original author(s) and the source, provide a link to the Creative Commons licence, and indicate if changes were made. The images or other third party material in this article are included in the article's Creative Commons licence, unless indicated otherwise in a credit line to the material. If material is not included in the article's Creative Commons licence and your intended use is not permitted by statutory regulation or exceeds the permitted use, you will need to obtain permission directly from the copyright holder. To view a copy of this licence, visit http://creativeco mmons.org/licenses/by/4.0/. The Creative Commons Public Domain Dedication waiver (http://creativecommons.org/publicdomain/ zero/1.0/) applies to the data made available in this article, unless otherwise stated in a credit line to the data. 
goal of achieving near-normoglycemia, has been shown in large prospective randomized studies (intensive glucose trials, IGT) to delay the onset and progression of DKD in patients with T2D [7]. On the other hand, IGC is thought to have controversial effects in reducing the macrovascular complications associated with T2D. The overall CONTROL (Collaborators on Trials of Glucose Lowering) meta-analysis based on 27,000 patients of the 4 major trials evaluating the effects of IGC on CVD (UKPDS, ACCORD, ADVANCE and VADT) showed that the more-intensive, as compared with the less-intensive glucose control, was associated with a $9 \%$ reduction of risk of major adverse cardiovascular events (MACE) and a mean reduction in hemoglobin $\mathrm{A} 1 \mathrm{c}$ (HbA1c) level of $0.9 \%$ [8]. Moreover, in the subset of diabetic population with pre-existing CVD, the cardiovascular benefit of IGC was completely absent (Hazard Ratio, $\mathrm{HR}=1.00,95 \% \mathrm{CI}$, 0.91-1.10) [9]. In a patient-level meta-analysis from the same four IGT, the relative risk for kidney events was reduced by $20 \%$ over 5 years of follow-up $(\mathrm{HR}=0.80$, $95 \% \mathrm{CI}, 0.72$ to 0.88 ) [10]. Although it is difficult to quantify the absolute risk reduction of renal complications because the associated hypoglycemia and polypharmacy may have outweighed their potential benefits, nonetheless lower HbA1c levels were associated with reduced onset or progression of DKD in three IGT.

The residual cardiorenal risk has been defined as the risk of progression of $\mathrm{CV}$ events (MACE or HF) and DKD that remains after the optimal glycemic control in T2D [11]. The first column of Fig. 1 shows the amount of removed risk (green) and residual risk (red) for MACE, DKD and HF in patients with T2D, as demonstrated by the results of IGT: residual risk after successful glycemic control ranges from $91 \%$ for MACE, to $80 \%$ for progression of DKD, and to $100 \%$ for HF. In quantitative terms, progression of DKD ranked first, with $20 \%$ removed risk, and hence $80 \%$ residual risk. However, the effects of IGC are more evident in terms of reducing albuminuria, as compared with harder renal endpoints such as ESKD, renal death, or fall in eGFR [10]. Despite all the efforts and sacrifices made by patients and their physicians to pursue an optimal glycemic control, it is quite frustrating to acknowledge the limited cardiorenal benefits obtained with IGC in T2D. In the last decade, the use of newer and innovative glucose lowering drugs surprisingly provided a significant reduction in the incidence of $\mathrm{CV}$ events, suggesting the possibility of cardiorenal protection beyond glycemic control [12]. Meta-analyses of the cardiovascular outcome trials (CVOT) reported to date suggest that glucagon-like peptide-1 receptor agonists (GLP-1RA) and sodium-glucose transporter-2 inhibitors (SGLT-2i) reduce risk of atherosclerotic MACE to a comparable degree in patients with T2D [13]. As for IGT, the residual cardiorenal risk can be defined as the risk of progression of CV events (MACE or HF) and DKD that remains after treatment with either GLP-1RA or SGLT-2i, as demonstrated by the results of CVOT. Accordingly, the removed risk of MACE is $13 \%$ for GLP-1RA and $12 \%$ for SGLT-2i (Fig. 1). However, the similarities between the two classes of drugs go no further. Figure 1 also shows that SGLT$2 \mathrm{i}$, as compared with GLP-1RA, removed twofold more risk (39\% vs 17\%) for kidney outcomes and fourfold more risk (33\% vs 9\%) for HF. Of note, the renal benefit of GLP1RA is confined primarily on a new onset of macroalbuminuria [5, 14]. Moreover, it should be stressed that these figures are obtained by comparing GLP-1RA or SGLT-2i with their respective placebos. To date, it is very unlikely that dipeptidyl peptidase-4 inhibitors have a clinically important cardiorenal benefits (Fig. 1): residual risk is 99\% for MACE, 100\% for kidney outcomes (excluding new albuminuria) [15], and 100\% for HF [13]. As CVOT were designed to obtain glycemic equipoise, in order to avoid the interfering influence of different glycemic control, it is still unknown whether the cardiorenal benefits of both intensive glucose lowering and newer drugs are additive. If so, we would expect a further amelioration of cardiorenal outlook in T2D, with the theoretical possibility that the removed risk with SGLT-2i, for example, would surpass $50 \%$ for kidney outcomes and $20 \%$ for MACE. Although the results of some multinational observational cohort studies suggest this possibility [16, 17], only controlled trials specifically designed to test this possibility would answer the question whether the cardiorenal protection by newer antihyperglycemic drugs is additive to that of optimal glycemic control in T2D.

In conclusion, the results of the many controlled trials (IGT and CVOT) so far concluded have shifted the therapeutic paradigm of T2D, from just, and sometimes obsessive, optimal glycemic control to a more comprehensive cardiorenal protection. In this perspective, and with the awareness that glycemic control may not be enough [18], clinicians are exhorted to prescribe antihyperglycemic drugs with proven cardiorenal benefits [19]. As prescriptions of these agents continue to stagnate, even among eligible patients [20], acknowledging the potential additive role for the blood glucose reduction in decreasing the cardiorenal risk of patients with T2D may overcome some residual reluctance of conservative specialists, who are still not ready to acknowledge that drugs might cut down diabetic cardiorenal complications independently of blood glucose reduction. 


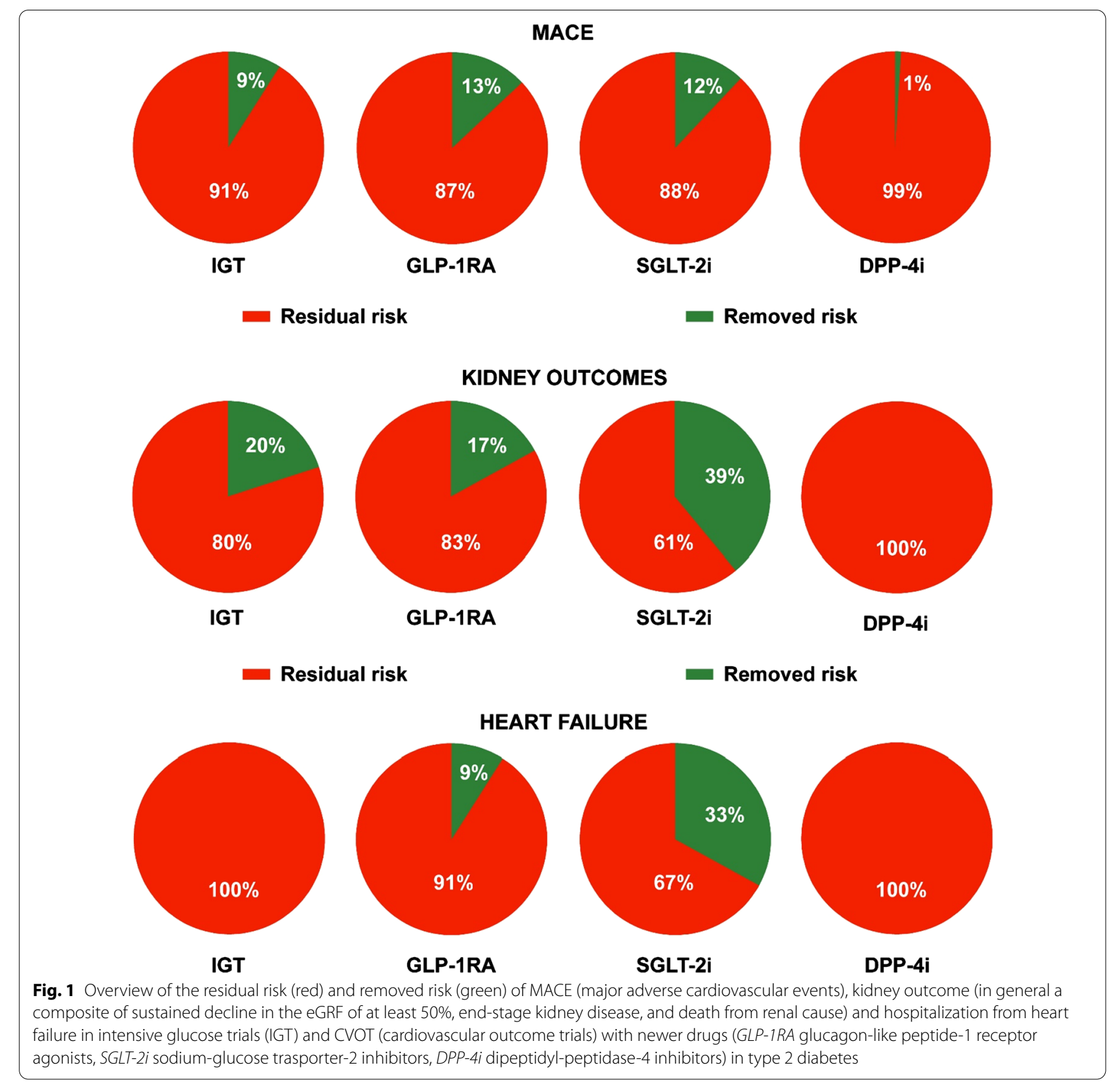

\section{Abbreviations}

SGLT-2i: Sodium-glucose transporter-2 inhibitors; GLP-1RA: Glucagon-like peptide-1 receptor agonists; DPP-4i: Dipeptidyl peptidase-4 inhibitors; ESKD: End stage kidney disease; HF: Heart failure; T2D: Type 2 diabetes; CV: Cardiovascular; MACE: Major adverse cardiovascular events; DKD: Diabetic kidney disease; eGFR: Estimated glomerular filtration rate; IGC: Intensive glucose control; IGT: Intensive glucose trials; CONTROL: Collaborators on Trials of Glucose Lowering; UKPDS: UK Diabetes Prospective Study; ACCORD: Action to Control Cardiovascular Risk in Diabetes; ADVANCE: The Action in Diabetes and Vascular Disease: Preterax and Diamicron Modified Release Controlled Evaluation; VADT: Veterans Affairs Diabetes Trial; HbA1c: Hemoglobin A1c; CVD: Cardiovascular disease; HR: Hazard Ratio; CVOT: Cardiovascular outcome trials.

\section{Acknowledgements}

Not applicable

\section{Authors' contributions}

DG wrote the manuscript. MIM, GB and KE critically reviewed the manuscript. All authors read and approved the final manuscript.

\section{Funding}

This study was funded in part by the "Associazione Salute con Stile", Naples, Italy.

Availability of data and materials

All data generated or analyzed during this study are included in this published article. 
Ethics approval and consent to participate Not applicable.

\section{Consent for publication}

Not applicable.

\section{Competing interests}

D.G. received honoraria for speaking at meetings from Novartis, Sanofi, Lilly, Astrazeneca, and NovoNordisk. M.I.M. received honoraria for speaking at meetings from AstraZeneca, Boehringer Ingelheim, and NovoNordisk. K.E. received honoraria for speaking at meetings from Novartis, Sanofi-Aventis, Lilly, AstraZeneca, Boehringer Ingelheim, and NovoNordisk. No other potential conflict of interest relevant to this article was reported.

\section{Author details}

${ }^{1}$ Division of Endocrinology and Metabolic Diseases, Department of Advanced Medical and Surgical Sciences, University of Campania Luigi Vanvitelli, Naples, Italy. ${ }^{2}$ Ph.D. of Translational Medicine, Chair of Endocrinology and Metabolic Diseases, Department of Advanced Medical and Surgical Sciences, University of Campania Luigi Vanvitelli, Naples, Italy. ${ }^{3}$ Diabetes Unit, Department of Advanced Medical and Surgical Sciences, University of Campania Luigi Vanvitelli, Naples, Italy.

Received: 14 January 2021 Accepted: 26 January 2021

Published online: 05 February 2021

\section{References}

1. Rawshani A, Rawshani A, Franzén S, et al. Risk factors, mortality, and cardiovascular outcomes in patients with type 2 diabetes. N Engl J Med. 2018;379:633-44

2. Wright AK, Suarez-Ortegon MF, Read SH, et al. Risk factor control and cardiovascular event risk in peoplewith type 2 diabetes in primary and secondary prevention settings. Circulation. 2020;142:1925-36.

3. Afkarian M, Zelnick LR, Hall YN, et al. Clinical manifestations of kidney disease among US adults with diabetes, 1988-2014. JAMA. 2016;316:602-10.

4. Fox CS, Matsushita K, Woodward M, Chronic Kidney Disease Prognosis Consortium, et al. Associations of kidney disease measures with mortality and end-stage renal disease in individuals with and withoutdiabetes: a meta-analysis. Lancet. 2012;380:1662-73.

5. Giugliano D, De Nicola L, Maiorino MI, Bellastella G, Garofalo C, Chiodini P, Ceriello A, Esposito K. Preventing major adverse cardiovascular events by SGLT-2 inhibition in patients with type 2 diabetes: the role of kidney. Cardiovasc Diabetol. 2020;19:35.

6. Ling W, Huang Y, Huang Y-M, Fan R-R, Sui Y, Zhao H-L. Global trend of diabetes mortality attributed to vascular complications, 2000-2016. Cardiovasc Diabetol. 2020;19:182.

7. Tuttle KR, Bakris GL, Bilous RW, et al. Diabetic kidney disease: a report from an ADA Consensus Conference. Diabetes Care. 2014;37:2864-83.

8. Turnbull FM, Abraira C, Anderson RJ, et al. Intensive glucose control and macrovascular outcomes in type 2 diabetes. Diabetologia. 2009:52:2288-98.
9. Barer Y, Cohen O, Cukierman-Yaffe T. Effect of glycaemic control on cardiovascular disease in individuals with type 2 diabetes with pre-existing cardiovascular disease: a systematic review and meta-analysis. Diabetes Obes Metab. 2019;21:732-5.

10. Zoungas S, Arima H, Gerstein HC, Collaborators on Trials of Lowering Glucose (CONTROL) group, et al. Effects of intensive glucose control on microvascular outcomes in patients with type 2 diabetes: a metaanalysis of individual participant data from randomised controlled trials. Lancet Diabetes Endocrinol. 2017:5:431-7.

11. Giugliano D, Maiorino MI, Bellastella G, Esposito K. Glycemic control in type 2 diabetes: from medication nonadherence to residual vascular risk. Endocrine. 2018;61:23-7.

12. Giugliano D, Maiorino Ml, Bellastella G, Chiodini P, Esposito K. Glycemic control, preexisting cardiovascular disease, and risk of major cardiovascular events in patients with type 2 diabetes mellitus: Systematic review With meta-analysis of cardiovascular outcome trials and intensive glucose control trials. J Am Heart Assoc. 2019;8:e012356.

13. Giugliano D, Giuseppe Bellastella G, Longo M, et al. Relationship between improvement of glycaemic control and reduction of major cardiovascular events in 15 cardiovascular outcome trials: a meta-analysis with metaregression. Diabetes Obes Metab. 2020;22:1397-405.

14. Zelniker TA, Wiviott SD, Raz I, Im K, Goodrich EL, Furtado RHM, et al. Comparison of the effects of glucagon-like peptide receptor agonists and sodium-glucose cotransporter 2 inhibitors for prevention of major adverse cardiovascular and renal outcomes in type 2 diabetes mellitus. Circulation. 2019;139:2022-31.

15. O'Hara DV, Parkhill TR, Badve SV, Jun M, Jardine MJ, Perkovic V. The effects of dipeptidyl peptidase-4 inhibitors on kidney outcomes. Diabetes Obes Metab. 2020. https://doi.org/10.1111/dom.14281.

16. Heerspink HJL, Karasik A, Thuresson M, et al. Kidney outcomes associated with use of SGLT2 inhibitors in real-world clinical practice (CVD-REAL 3): a multinational observational cohort study. Lancet Diabetes Endocrinol. 2020:8:27-35.

17. Udell JA, Yuan Z, Rush T, Sicignano NM, Galitz M, Rosenthal N. Cardiovascular outcomes and risks after initiation of a sodium glucose cotransporter 2 inhibitor: results from the EASEL population-based cohort study (Evidence for Cardiovascular Outcomes With Sodium Glucose Cotransporter 2 Inhibitors in the Real World). Circulation. 2018;137:1450-9.

18. Giugliano D, Longo M, Scappaticcio L, Caruso P, Esposito K. Sodium-glucose trasporter-2 inhibitors for prevention and treatment of cardiorenal complications of type 2 diabetes. Cardiovascular Diabetol. 2021;20:17.

19. American Diabetes Association. 10. Cardiovascular disease and risk management: Standard of medical care in diabetes - 2021. Diabetes Care. 2021:44(Suppl 1):S125-50.

20. Schernthaner G, Shehadeh N, Ametov AS, et al. Worldwide inertia to the use of cardiorenal protective glucose-lowering drugs (SGLT2i and GLP-1RA) in high-risk patients with type 2 diabetes. Cardiovasc Diabetol. 2020;19:185.

\section{Publisher's Note}

Springer Nature remains neutral with regard to jurisdictional claims in published maps and institutional affiliations.

Ready to submit your research? Choose BMC and benefit from

- fast, convenient online submission

- thorough peer review by experienced researchers in your field

- rapid publication on acceptance

- support for research data, including large and complex data types

- gold Open Access which fosters wider collaboration and increased citations

- maximum visibility for your research: over 100M website views per year

At BMC, research is always in progress.

Learn more biomedcentral.com/submissions 